\title{
HIGH PERFORMANCE CONCRETE FOR HIGH-RISE BUILDINGS: SOME CRUCIAL ISSUES
}

\author{
Vijay R Kulkarni \\ Principal Consultant, RMCMA \& Past President, Indian Concrete Institute
}

\begin{abstract}
High-rise building construction has been an important driver for the revitalization of urban centers throughout the world. The paper briefly summarizes the unprecedented growth in tall building construction across the globe during the past few decades. Review of tall building scenario reveals two interesting trends. Firstly, the centre of gravity of tall building construction which had already shifted from North America to Asia, is getting strengthened in the latter region, and secondly, structural concrete has emerged as a dominant material of construction of tall buildings, either in a stand-alone form or as a part of composites, surpassing structural steel. The use of High-Strength, HighPerformance Concrete (HSC/HPC) has proved to be a boon for high-rise building construction. HSC and HPC are engineered concretes having vastly improved properties. With such type of concretes, it is possible to achieve high compressive strengths that are useful in reducing the sections sizes of members and high modulus of elasticity for controlling deflections. Further, these concretes can be designed to provide immensely improved long-term durability. Thanks to the availability of a latest generation chemical admixtures, it is now possible to pump HSC/HPC to greater heights. In India, the scarcity of land in metropolitan centers is driving the land prices sky high and is compelling developers and builders to build taller buildings. With the rise in the stock of tall buildings in India, the use of HSC/HPC is also on the rise. The author briefly reviews the broad trends in the use of HSC/HPC in India with specific reference to the projects he has been associated with recently. Selection of appropriate ingredients of concrete and mix proportioning methodology are the crucial parameters for achieving the desired properties of HSC/HPC. Even minor variations in the properties of ingredients and testing regime affect the fresh and hardened properties of concrete. For HSC/HPC the author makes a strong plea to use manufactured sand having lower variations in its fines content. Considering that rheology of HSC/HPC is of critical importance, the author emphasizes that it is essential to resolve the cement-admixture compatibility issue in the initial stage itself. He suggests that use of cement having low $C_{3} A$ and low $C_{4} A F$ contents would prove to be beneficial. Finally, the author highlights the urgent need of developing appropriate guideline documents for HSC/HPC in India.
\end{abstract}

Keywords: High-Strength, High Performance Concrete, Durability, Temperature Control, Fire Resistance

\section{INTRODUCTION}

Twin problems of population growth and rapid urbanization have assumed serious dimensions in recent times. In 1950, 30 percent of the world's population was urban, and $70 \%$ was rural. This trend is likely to get reversed by 2050 . According to the latest report of the United Nations on World Urbanization, continuing population growth and urbanization are projected to add 2.5 billion people to the world's urban population by 2050 , with nearly $90 \%$ of the increase concentrated in Asia and Africa ${ }^{1}$. Just three countries - India, China and Nigeria - together are expected to account for 37 per cent of the projected growth of the world's urban population between 2014 and 2050. In this projected growth, India's share will be highest with 404 million urban dwellers, followed by China with 292 million and Nigeria with 212 million. Two Indian cities - Delhi NCR and Mumbai - are amongst the world's most populous cities having population in excess of 20 million.
Population growth is responsible for migration of people to urban centers in search of livelihood. Better opportunities in urban centers drive more and more people to migrate to cities. Thus, urbanization is helpful in creating power houses of economic development, contributing substantially to the national economy. The mid-term appraisal of the Eleventh Plan projected the urban share of GDP at 62-63 percent in 2009-10. By 2020, this share is likely to increase to around 70-75 according to Barclay's report ${ }^{2}$. However, rapid urbanization also creates a number of social, economical and cultural problems. Rising slums and scatter population in urban centers are the direct results of rapid urbanization. Besides, faster pace of urbanization creates tremendous pressure on the existing urban services - water supply, transportation, sanitation, etc.

Since land is a scare resource, especially in urban areas, the tempo of economic development can be sustained if intense development is allowed by permitting "vertical" growth. This means allowing more F S I (Floor Space Index). 


\section{WHAT IS A TALL BUILDING?}

According to the Criteria for defining and measuring of tall buildings published by the Council for Tall Buildings and Urban Habitat (CTBHU) ${ }^{3}$, there is no "absolute definition of what constitutes a tall building". It is a building that exhibits some element of "tallness" in one or more of the following three categories:

(i) Height relative to context: e.g. A 14-storey building may not be considered tall in a city like Hong Kong; but the same may be considered distinctly taller in a rural area

(ii) Proportion: e.g. A building may not be particularly tall, but it could be slender enough to give the appearance of a tall building.

(iii) Tall building technologies: e.g. buildings having specific vertical transport technologies, structural wind bracing system may be classified as tall building.

CTBHU has developed specific criteria on measuring the height of buildings. Generally speaking, height is measured from the level of the lowest, significant, open-air, pedestrian entrance to the architectural top of building including spires, but not including antennae, signage, flagpoles or other functional equipment.

The draft Indian Standard on Criteria for Structural Safety of Tall Buildings states that it is applicable to building heights greater than $45 \mathrm{~m}$, but less than $250 \mathrm{~m}^{4}$. It may be inferred from this that in India buildings with heights greater than $45 \mathrm{~m}$ can be considered as tall buildings.

Incidentally, CTBHU has made two more categories in the tall building sphere. It defines "Supertall" as a building over $300 \mathrm{~m}$ in height and a "Megatall" as a building over $600 \mathrm{~m}$ in height.

It is reported that as of June 2015, there were 91 Supertall and 2 Megatall buildings fully completed and occupied globally ${ }^{5}$.

\section{TALL BUILDINGS SCENARIO}

\subsection{Brief History}

Home Insurance Building located in Chicago is considered the first skyscraper. This building constructed in 1885 in cast iron had a height of $55 \mathrm{~m}$ ( 12 storeys) ${ }^{6}$. Another landmark skyscraper, Empire State Building completed in 1931 had a height of $382 \mathrm{~m}$.

In the sphere of concrete, Ingalls Building in Cincinnati, the 15-storey building built in 1903 by A O Elzner is reported to be the first concrete skyscraper ${ }^{7}$.

The trend of high-rise building construction began with major cities like New York and Chicago in the USA since the first half of the 20th century. The change in city skyline of New York over the past nearly one-and-a-half century (1879 to 2013) depicted in Fig 1 is a clear testimony of this trend.

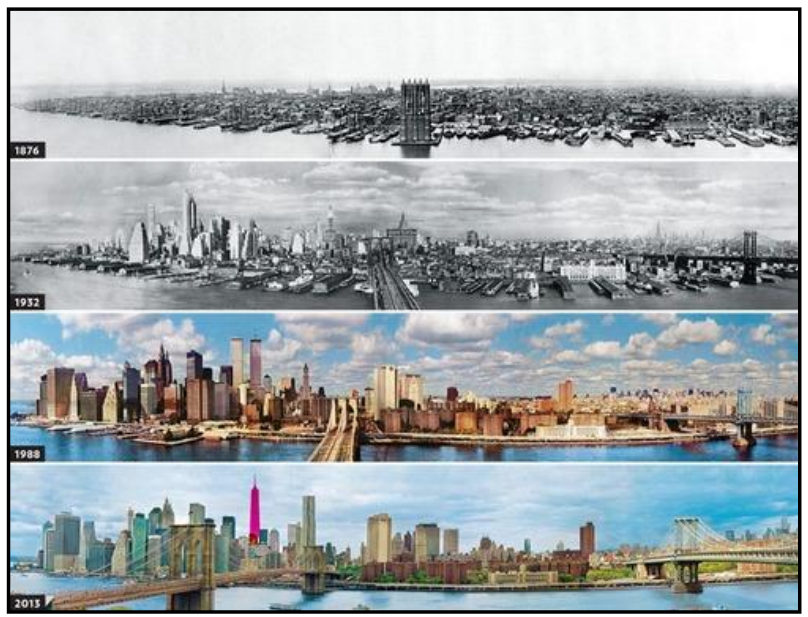

Fig 1. Evolution of New York city Skyline 1879-2013 (Source: http://theyard.nyc/blog/the-evolution-of-the-newyork-city-skyline)

The construction of tall buildings gathered momentum in the second half of the $20^{\text {th }}$ century. According to the latest data published by the CTBHU, the total number of tall building having heights exceeding 200-m reached the 1,000 mark in $2015^{5}$. It is evident from Fig 2 that although it took 95 years to achieve the 1000 -mark in the 200 -m plus tall buildings register, the spurt in activities in this field commenced only from the year 2000 onwards. During the past 15 years, the number of 200-m tall buildings increased from 265 (2000) to 1040 (2015) - an increase of nearly $392 \%$ ! The addition of 106 numbers to the $200-\mathrm{m}$ plus tall buildings count during the year 2015 was itself a world record. This trend is expected to gather further momentum.

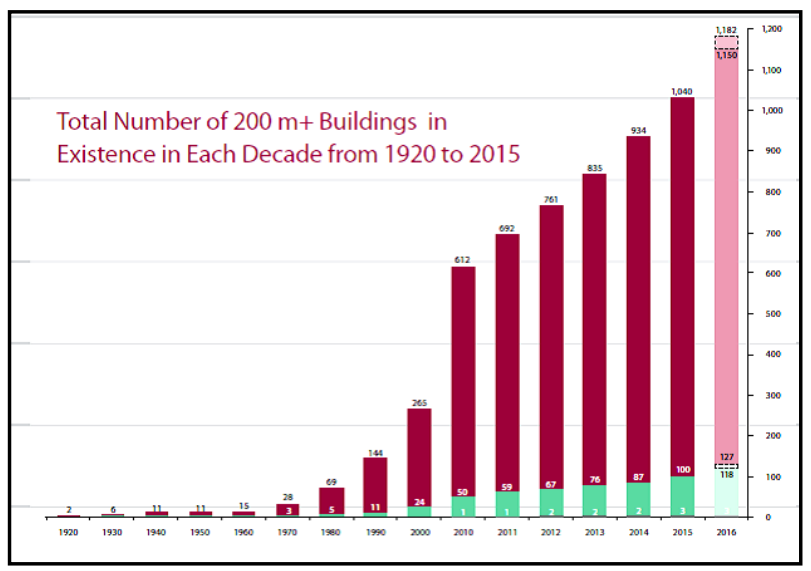

Fig 2 Number of 200-m plus tall buildings in the world exceeded the 1000 mark in 2015 (source: CTBHU)

\subsection{Perceptible Shifts in Locations of Tall Buildings}

It is interesting to note that North America no longer dominates the tall building sphere. By the turn of last century, the centre of gravity of construction of tall buildings had shifted from North America to Asia. In the year 1930, all the 100 tallest buildings in the world were located in North America. This number has come down to just 17 in 2015, Fig 3. The place earlier occupied by North America in the 100 tallest buildings category is now occupied by Asia (48), followed by Middle East (28), Fig $3^{5}$. 


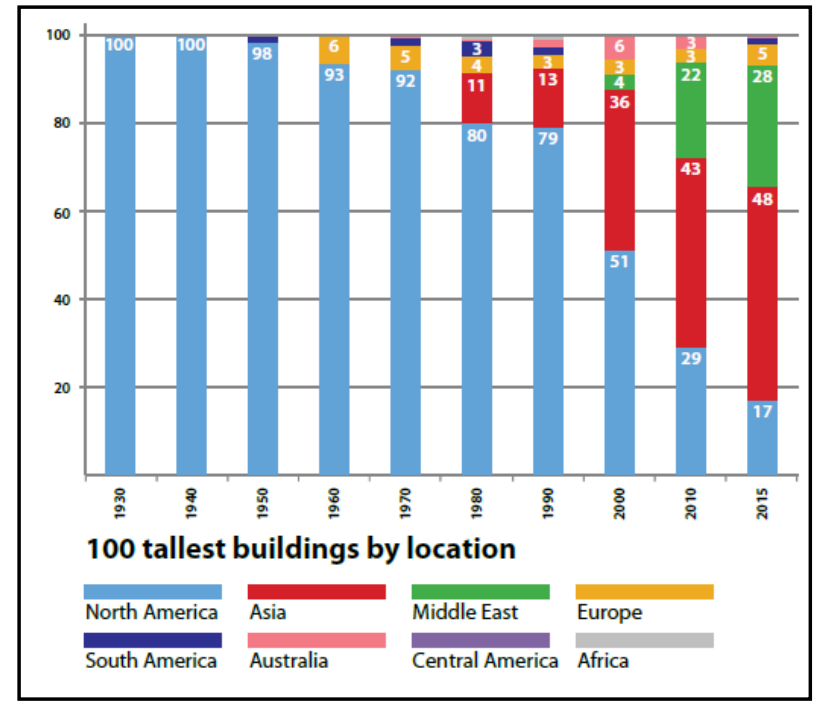

Fig 3 Perceptible shift from North America to to Asia (Source: CTBHU)

Asia has been the major driver for the growth in this sector since the year 2000. Asia has been outperforming the other regions. Out of the 106 tall buildings completed during the year 2015, 81 were from Asia, representing $76 \%$ of the total stock.

For the past few years, China has been the leader in tall building construction. According to the CTBHU report, the number of 200-m-plus tall building completed in China during 2015 was 62 . Out of the 29 Chinese cities with 200m-plus tall building completions, Nanjing, Nanning and Shenzhen had the most with five each.

\subsection{Concrete Scores over Other Materials}

There is a clear shift in the use of materials of construction for tall buildings. From the beginning of tall building construction, structural steel was the preferred choice. However, since 1980, there is a perceptible shift from steel to concrete and composites! The trend has become more pronounced in recent years, Fig 4.

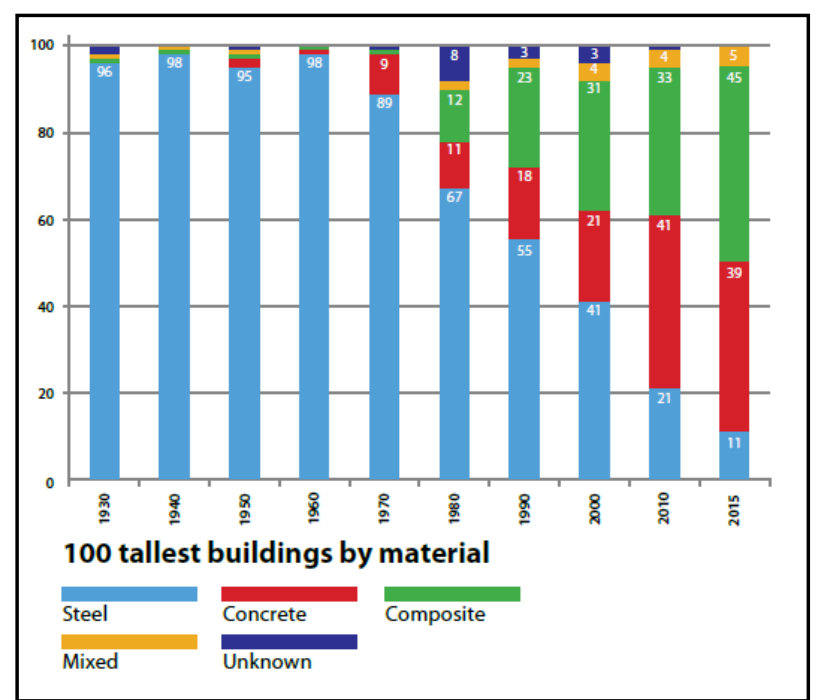

Fig 4 Perceptible shift in the material of construction - from steel to concrete composites (source: CTBHU)
It is interesting to note that 2015 saw a spike in the number of buildings completed with concrete structures -52 out of $106(49 \%)^{5}$. This is a dramatic increase over 2014 , when only 39 out of 99 were completed in concrete (39\% of total). All-steel towers were very scanty in 2015 , with only three 200-m-plus completions around the globe.

\section{WHY CONCRETE?}

During the initial phase of tall building construction, structural steel was the preferred material, especially in North America. This was because the material was available in the required shapes and sizes and the mechanized tools were available for transporting and placing the same in position at site. As the advances in concrete technology became available to the industry, the shift from steel to concrete commenced.

Technological advances in the following four main areas were mainly responsible for establishing the dominance of concrete over steel in the tall building sphere.

- Advances in high-strength concrete, highperformance concrete, self-compacting concrete

- Advances in chemical admixtures

- advances in transport and delivery of concrete

- Advances in formwork system

\subsection{High-strength, High-performance Concrete}

The development and use of high-strength concrete (HSC) has proved to be a boon for high-rise building construction. It has been established that the use of HSC in columns, shear walls, transfer beams, etc. helps in reducing the section sizes and the percentage of reinforcement. The twin reduction in the quantity of concrete and steel not only results in bringing down the materials costs but the useable floor space is also increased, thereby yielding higher revenues.

As the use of HSC gathered momentum, properties other than compressive strength also became important. This gave rise to the evolution and use of what is today known as highperformance concrete (HPC).

High-strength, high-performance concrete invariably uses one or more supplementary cementitious materials such as fly ash, ground-granulated blast-furnace slag, silica fume, rice husk ash. In addition, the water-to-binder ratio of HSC/HPC is also low. Both these characteristics of $\mathrm{HSC} / \mathrm{HPC}$ are responsible in improving the long-term durability of HSC/HPC. This has been proved from a plethora of research conducted globally. The improvement in long-term durability of concrete will indirectly improve the sustainability of construction.

ACI 363R:2010 reports that in many areas and for many uses, the benefits of HSC more than compensate for the increased costs of raw materials and quality control ${ }^{8}$.

The technical and economic benefits of HSC/HPC were conducive to their use in tall buildings. 


\subsection{Chemical Admixtures}

Till the first half of 20th century, lignosuphonate-based chemical admixture was the main source of reducing water demand in concrete. With this type of admixture, it was possible to reduce the water demand in concrete to the extent of around 5\% or so. It was in the 1960s that the naphthalene and melamine sulphonate-based admixtures emerged on the scene. These admixtures were able to reduce the water demand in concrete substantially - by around $20 \%$ or so. This improvement in the chemical admixture technology gave a boost to the development of high-strength and high-performance concretes. With such admixtures, it was also possible to pump the concrete at greater heights.

Recently, polycarboxyl -based (PCE-based) admixture, which is considered to be the fourth-generation type chemical admixture is available. With this admixture, it is possible to reduce water demand in concrete by as much as $40 \%$. The use of such admixture was conducive to the development of HSC/HPC on the one hand and pumping of concrete on the other.

\subsection{Self-compacting Concrete}

Self-compacting concrete (SCC) is a highly workable and flowable mix, which flows around obstructions, encapsulates congested reinforcement, and fills up the forms completely under its self weight without segregation or excessive bleeding. The use of SCC increases speed of construction, reduces construction joints, provides better surface finish, reduces noise, and results in reduction in site manpower.

These benefits of SCC have been found to be useful in tall building construction, especially for elements having congested reinforcement. Further, with SCC it is possible to place concrete in elements having greater lift heights. This helps in speeding up construction.

\subsection{Advances in Concrete Delivery System}

Until the early $20^{\text {th }}$ century, concrete was mixed on the job site and transported from the mixer to the formwork, either in wheelbarrows or in buckets. In developing countries like India it was transported on headload by a long chain of labourers.

In the initial phase concrete used to be placed with the use of buckets and crane. However, as the heights increased, this system was found to be cumbersome and time-consuming.

First concrete pump was patented in Holland in 1932 by Jacob Cornelius Kweimn. The popularity of pumps grew in the 1930s and 1940s. After World War II, many European countries had to rebuild their bombed cities, increasing the need for concrete pumps.

The introduction of hydraulics during the 1950s revolutionized the concrete pumping industry. Since then there have been many developments in this field. Today, modern concrete pumps have enormous power, high capacity and a reliable hydraulic system for pumping. They can pump concrete vertically more than $500 \mathrm{~m}$ and deliver it horizontally up to $500 \mathrm{~m}$ or so. Their outputs range from between 30 to $150 \mathrm{~m}^{3}$ per hour. The pumping records are getting broken quite often. The latest was the pumping concrete at a height of $606 \mathrm{~m}$ for the Burj Dubai tower ${ }^{9}$.

\subsection{Advances in Formwork Systems}

Traditionally, forms and supporting system were made up of wood. As the technology advanced, new materials were introduced. Forms became a combination of wood, plywood, steel, aluminium. plastic, fibreglass, etc. The supporting structure and bracings which were earlier made up of wood were replaced with steel trusses, H-frames, etc. Job-built forms which are built by assembling individual component, piece by piece are now available. Prefabricated job-built forms are used for mass production where several reuses are possible.

Formwork affects the quality of concrete. Poor quality formwork may lead to excessive deflection and bulging of concrete. Misalignment can destroy integrity of structure. Quality of surface finish gets directly affected by the form material. Poor workmanship may lead to leakages and honeycombs. It is therefore essential to have a properly designed formwork system, which is erected with due consideration to quality and safety.

Fortunately, a number of proprietary modular formwork systems are now available. Broadly speaking the available systems can be grouped into following five categories:

- Table formwork or flying formwork

- $\quad$ Slip formwork

- Travelling formwork

- Tunnel formwork

- Jump formwork

Advances in the formwork systems have been of great value in the construction of high-rise buildings. The use of advanced systems has helped in achieving higher speed of construction and better quality of concrete. Of course, for this purpose the construction team needs to take proper care in the selection of appropriate formwork system, its design, erection and dismantling.

\section{TALL BUILDINGS IN INDIA}

No authentic data is available on the number of tall building constructed in India. Some unauthenticated data are available on the Internet. It is reported that 84 tall building with heights greater than $140 \mathrm{~m}$ have been completed and 157 buildings with heights greater than $130 \mathrm{~m}$ or floors more than 40 are under construction ${ }^{10}$. It is also reported that 20 buildings with heights greater than $150 \mathrm{~m}$ are on the hold and some 74 buildings with heights greater than $150 \mathrm{~m}$ have been proposed. 
Although authentic data on tall buildings are not available, one is able to notice the changing skylines in major metropolitan cities of India. Fig 4 shows the changed skyline of central Mumbai where some of the tall buildings have been constructed or under construction.

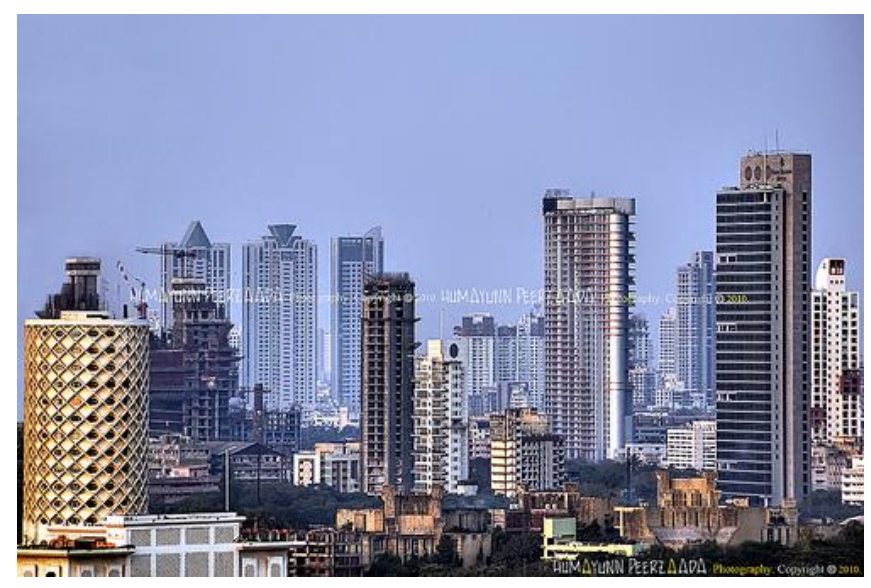

Fig 4. Changing skyline of central Mumbai

Incidentally, a Special Issue of the Indian Concrete Journal devoted to Tall Buildings in Mumbai described in detail the design and construction aspects of three tall buildings in the city completed in late 1990s.

Looking at the constrains in the availability of land in major metropolitan centers and business districts in the country, it is obvious that the demand for tall buildings is bound to grow in the near future. However, no reliable estimates of projected growth are available.

\section{HIGH-STRENGTH, HIGH-PERFORMANCE} CONCRETE FOR TALL BUILDINGS

\subsection{High-strength Concrete}

The use and definition of high-strength concrete has witnessed continuous upward revisions. In the USA, 35 $\mathrm{MPa}$ concrete was considered HSC in the 1950s. In the 1960s, HSC threshold raised to M50 and in 1970s it was M60. According to ACI 363:2010 compressive strengths approaching 20,000 psi (138 MPa) have presently been used in cast-in-place buildings.

Even in India, the Bureau of Indian Standard's code, IS 456, has changed its definition of HSC from time to time as shown below:

$\begin{array}{ll}\text { IS Revisions } & \text { HSC grade designation } \\ \text { IS 456: 1978: } & \text { M40, M45, M50, M55, M60 } \\ \text { IS 456: } 2000 & \text { M60, M65, M70, M75, M80 } \\ \text { IS 456: } 2000 & \text { M65, M70, M75, M80, M90, M100 } \\ \left.\text { ( }^{\text {th }} \text { amendment }\right) & \end{array}$

High-strength concrete is widely available throughout the world in including India, and its use continues to spread. Most of the tall buildings constructed in recent past have some structural contribution from HSC in vertical column and wall elements.

\subsection{High-performance Concrete}

While using HSC, the emphasis gradually shifted from compressive strength to other properties of concrete such as high modulus of elasticity, high density, low permeability, higher resistance to aggressive chemicals, etc. It was considered more logical and prudent to describe such concrete by a more widely embracing term - highperformance concrete (HPC).

HPC is aptly described in the following ACI definition: "HPC is the concrete meeting special combinations of performance and uniformity requirements that cannot always be achieved routinely using conventional constituents and normal mixing, placing and curing practices."

HPC has a number of advantageous properties compared to the conventional normal strength concrete (NSC). HPC mix can be engineered based on the specific performance requirements, such as strength, low heat of hydration, shrinkage and creep; high impermeability; high workability; resistance to high abrasion, high toughness; etc.

The ingredients of NSC and HPC are essentially the same cement, aggregates, water and chemical and mineral admixtures. According to Neville and Aitcin, the difference lies in the knowhow - i.e. the knowledge of properties of ingredients and their interaction ${ }^{11}$.

In India, HPC has been adopted recently in the construction of a few major projects, like the Inner Containment Dome of the Reactor Building, Kaiga Project Unit-2 (Kaiga-2), Rajasthan Atomic Power Project Unit-3 (RAPP-3), J.J flyover, Mumbai, and Worli-Bandra sea link.

For tall buildings too, HPC is an appropriate material and the same is being used at certain locations in India.

\section{HSC/HPC: SOME CRUCIAL ISSUES}

In case of HSC/HPC, attempts are made to extract the maximum possible potential from the properties of different ingredients of concrete. In this exercise, the properties of the ingredients getting utilized are usually pushed to their extremes. It is therefore essential to have - what Aitin and Neville describes - the full "knowhow" of individual properties of ingredients, their integration with each other and the effect of variations of these properties on the final properties of HSC/HPC. As the compressive strength is increased, such issues become more crucial. This is more so for grades higher than M60. The following discussion on the crucial issues is based on the authors' recent laboratory and field experience in the production of concretes of grades M60, M70, M80 to M95. 


\subsection{Effect of Variation in Properties of Ingredients}

\section{Cement}

All types and brands of OPC may not be suitable for HSC/HPC. While from the strength perspective, high $\mathrm{C}_{3} \mathrm{~S}$ and $\mathrm{C}_{3} \mathrm{~A}$ cement may be desirable, from the rheological angle, low $\mathrm{C}_{3} \mathrm{~A}$ and $\mathrm{C}_{4} \mathrm{FA}$ cements may prove to be better. It is reported that besides Blaines's fineness of cement, its alkali, suphate and $\mathrm{C}_{3} \mathrm{~A}$ contents as well as the crystal symetry of the latter also affect cement-SCM-admixture compatibility at low water-binder ratio ${ }^{12}$. Problems of cement-SCM-chemical admixture compatibility are reflected in the sudden loss of slump and/or slump retention over longer duration. As recent experience has indicated this may result in serious problems in pumping of concrete such as choking of pump pipelines, difficulties in compaction and finishing, etc.

Therefore the compatibility issue of cement and chemical admixture on the one hand and cement, SCM and chemical admixture on the other hand needs to be resolved satisfactorily at the initial stage only during lab trials. For the selection cement, SCM and chemical admixture for a particular project it is essential to evaluate different available brands in lab trials. Based on the lab trials, final decision should taken on procuring the raw materials of concrete.

Considering the crucial role of cement in determining the strength and rheology of concrete, Aitcin and Mindess in a recent article suggest that the cement industry should consider producing two types of ordinary Portland cement, one for water-binder ratio lower than 0.5 and the other higher than $0.5^{13}$. The parameters suggested by the two experts are given in Table 1.

Table 1 : Suggested parameters for two types of OPC by Aitcin and Mindess ${ }^{13}$

\begin{tabular}{|l|l|l|}
\hline \multirow{2}{*}{$\begin{array}{l}\text { For concretes with } \\
\text { w/c }<0.5\end{array}$} & $\mathrm{C}_{3} \mathrm{~A}$ & $6 \% \max$ \\
\cline { 2 - 3 } & Fineness & $350-400 \mathrm{~m}^{2} / \mathrm{kg}$ \\
\hline \multirow{2}{*}{$\begin{array}{l}\text { For concretes with } \\
\text { w/c }>0.5\end{array}$} & $\mathrm{C}_{3} \mathrm{~A}$ & $8 \% \max$ \\
\cline { 2 - 3 } & Fineness & $400-450 \mathrm{~m}^{2} / \mathrm{kg}$ \\
\hline
\end{tabular}

\subsection{Fine Aggregates}

In view of the scarcity of river sand in metropolitan areas and other big cities in India, the use of manufactured sand as an alternative to the river sand has emerged and its use has been growing. The mix proportioning of HSC/HPC can certainly be done with manufactured sand; however, care should be taken to avoid the use of crushed rock fines (CRF) - a waste product known as quarry dust. As the fractions passing 300, 150 and 75 micron sieves play a crucial role in determining the water demand in concrete, care shall be taken to exercise limits on these fractions. Fig 5 shows typical variations of fines passing through the three sieves from a project in Mumbai during monsoon period when severe shortage of sand was experienced..

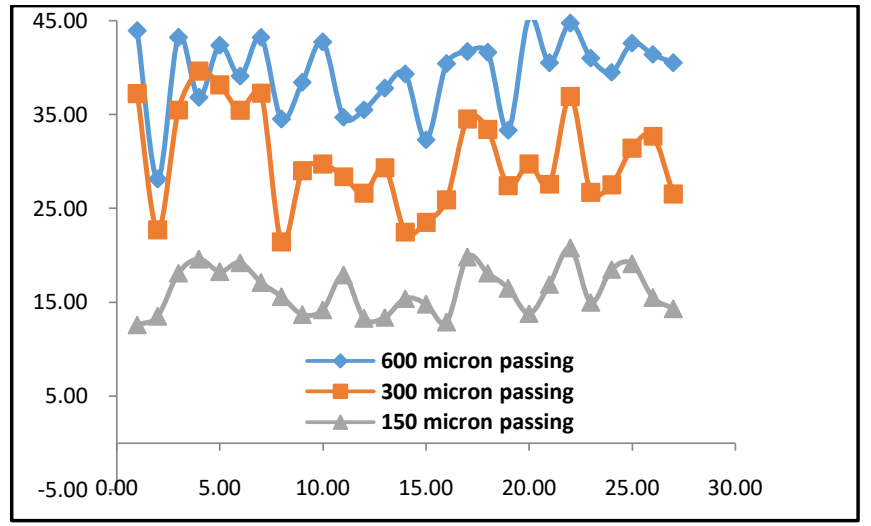

Fig 5 Variation in \% passing 150, 300 and 600 micron sieves

\subsection{Supplementary Cementitious Materials}

Use of one or more supplementary cementitious materials (SCM) become essential to achieve the strength, durability and other properties of HSC/HPC. Two major categories of SCMs used today include: fly ash and ground granulated blast-furnace slag. The pozzolanic and/or hydraulic properties of SCMs help a great deal in improving the fresh and hardened properties of HSC/HPC. These mainly include improved workability and pumpability, reduction in water demand and in the permeability of concrete. Moreover, use of SCMs has proved to be cost-effectiveness, owing to the reduction in cement content.

In addition to these two SCMs, HSC/HPC needs addition of a finer variety of SCMs - either condensed silica fume, ultrafine GGBS, high-reactive metakaolin, rice husk ash or a combination of thereof. The finer varieties of SCMs are highly reactive and their incorporation in the concrete mix helps in achieving the desired properties of strength and durability at different ages for HSC/HPC.

\subsection{Chemical Admixture}

HSC/HPC necessarily include one or more chemical admixture. The introduction of $4^{\text {th }}$ generation admixture, i.e. polycarboxylate-based (PCE-based), which has a capability of reducing the water demand by around $35-40 \%$ has been instrumental in producing concretes having very low waterbinder ratio that are pumpable too.

\subsection{Mix Proportioning of HSC/HPC}

High-strength concrete mixture proportioning is a more critical process than proportioning normal-strength concrete mixtures. The use of SCMs and chemical admixtures, and the attainment of a low water-binder ratio are considered essential in high-strength concrete mix proportioning. ACI 363R:2010 provides detailed guidelines ${ }^{8}$. Aitcin has also proposed a methodology on mix proportioning of HPC.

Many trial batches are often required to generate the data that helps in identifying the optimum mix proportions of HSC/HPC to be used. 


\subsection{Durability of Concrete used for Tall buildings}

Ensuring long-term durability of concrete will be of paramount importance in case of tall buildings. This is because the maintenance, repair and restoration of tall buildings will be comparatively difficult, time consuming and costly. It is therefore appropriate to introduce stringent durability criteria for concrete used for Tall Buildings. The author would like to suggest the following threshold values of the most commonly used durability test methods:

- $\quad$ Rapid chloride ion permeability test (ASTM 1202)

- Foundations: Not more than 1000 Coulombs

- Superstructure: Not more than 1500 Coulombs

- Water penetration test (DIN 1048)

- Foundations: $15 \mathrm{~mm} \max$

- Superstructure: $20 \mathrm{~mm}$ max.

\subsection{Quality Control and Testing HSC/HPC}

Since there are likely to be variations in the properties of different ingredients of concrete, strict quality control and quality assurance procedures needs to be followed meticulously during the production, transport and placement of concrete. Otherwise these variations will get reflected in the final product. In case of HSC/HPC more stricter QA \& QC procedures need to be followed since this type of concrete is very sensitive to variations in properties of ingredients.

For ensuring quality of concrete produced from ready-mixed concrete plants, the Quality Council of India (QCI) has already developed a comprehensive framework of audit of the plant and equipment as well as the production control process $^{15}$. It will be appropriate to have the plant facility certified under the QCI Scheme. However, this may not suffice. The QCI audit happens only once in 6 months. For plants producing HSC/HPC, this is too long a period. It is therefore essential to conduct comprehensive production control audit every month for plants producing HSC/HPC.

It is now well established that measured strength of HSC/HPC is more sensitive to testing variables. ACI 363 reports that measured strengths between laboratories were as high as $10 \%$. ACI $363.2 \mathrm{R}$ provides a detailed guidance on testing and quality control of HSC.

The cost of QA \& QC in producing HSC/HPC will be comparatively high. However, considering the resulting benefits of improved ability to produce good quality concrete with reduced variations, this will prove to be more rewarding.

\subsection{Temperature Control in Massive Concrete}

\section{Elements}

Thick raft foundations are needed to support tall buildings. Shear walls, columns and transfer beams have massive sections. Concrete used in such massive elements may lead to the evolution of high heat of hydration. Concrete mixes used for such elements usually contain high cementitious materials content, low water-binder ratio and sometimes lower maximum size of aggregate (the latter in view of heavy congestion of steel). The design of such concretes shall be done in such a manner that the peak temperature in concrete shall not exceed $70^{\circ} \mathrm{C}$ and that the thermal gradient within the concrete mass does not exceed $20^{\circ} \mathrm{C}$.

While appropriately designed mock trials shall be conducted prior to actual concreting to demonstrate that these parameters are satisfied, temperature monitoring shall be done in massive elements by installing adequate number of temperature sensors to record temperature data on a continuous basis to demonstrate that the temperature rise and thermal gradients are within the specified limits.

\subsection{Fire Resistance of Concrete in Tall Buildings}

Fire may be a serious hazard in case of tall buildings. In view of concrete's low thermal conductivity and high heat capacity, it generally provides better fire protection when compared with other construction materials such as steel, aluminum, wood, etc. However, the behavior of HSC in fire is slightly different than that of normal-strength concrete. In case of fire, HSC has a tendency to exhibit explosive spalling.

While densification of concrete microstructure owing to the combined use of low water-binder ratio and large percentage of SCMs helps in achieving high strength and durability, this very densification of microstructure makes concrete vulnerable to explosive spalling during fire.

It is observed that polypropylene fibres if incorporated in concrete melt at about $140-160^{\circ} \mathrm{C}$, creating "channels" for steam pressure in concrete to escape, thereby releasing pore pressure which help in preventing spalling. Further, results from fire resistance studies clearly show that the layout of ties and confinement of columns have an influence on the fire performance of HSC columns. Studies done at NRC Canada and by Prof Kodur suggest that provision of bent ties at $135^{\circ}$ back into concrete core and closer tie spacing are helpful in protecting concrete in during fire ${ }^{14}$.

\section{CONCLUSION}

India is poised to witness considerable growth in tall building construction and the use of HSC/HPC is bound to increase. Considering the intricacies involved in the design, production and quality control of HSC/HPC, it is suggested that a comprehensive document should be prepared and published for the guidance of all stakeholders involved in tall buildings. 


\section{REFERENCES}

[1] World Urbanization Prospects: The 2014 Revision Highlights, Published by United Nations, NewYork, 2014.

[2] Barcleys Report, "Urban population to contribute 70$75 \%$ of India's GDP by $2020 "$ Capital Market, Business Standards, March 20, 2014.

[3] Criteria for the Defining and Measuring of Tall Buildings, Council for Tall Buildings and Urban Habitat (CTBHU), Chicago, USA.

[4] CED 38 (10639) WC, Criteria for Structural Safety of Tall Buildings (Draft) 2016.

[5] Gabel, Jason. Tall Trends of 2015 and Forecasts for 2016, CTBHU Year in Review, Council for Tall Buildings and Urban Habitat (CTBHU), Chicago, USA.

[6] Dinu, Florea. Tall Buildings, Sustainable Construction under Natural Hazards and Catastrophic Events, February 2014.

[7] Ali, Mir M. Rise of Concrete High-rise, The Indian Concrete Journal, August 2001, 497-506.

[8] ACI 363R:2010, Report on High Strength Concrete, American Concrete Institute, USA.

[9] __ New heights reached in Concrete Pumping, World Pumps, September 2009, pp. 18-20.

[10] https://en.wikipedia.org/wiki/List_of_tallest_buildings_ in_India.

[11] Aitcin P C and Neville, Adam, High-performance concrete demystified, Concrete International, January 1993, pp. 21-23.

[12] Aiticin P.C. Jolicoeur, C., Macgregor, J. Superplasticizers: How they work and why they occasionally don't. Concrete International, 1994, Vol. 15 , No.5, pp.45-52.

[13] Aitcin, P. C. and Mindess, Sidney, Back to the Future, Concrete International, May 2015, pp.37-40.

[14]Kodur, V., Properties of concrete at elevated temperature, ISRN Civil Engineering Volume 2014, Article ID 468510, p. 15.

[15] Kulkarni V R, Mallick, A K and Kurian Jose, Upgraded QCI quality scheme for ready-mixed concrete, ICI Journal, 